\title{
El dios que nace de la roca. Aspectos comparativos del mito del nacimiento de Mitra
}

\author{
Juan Antonio Álvarez-Pedrosa \\ Universidad Complutense de Madrid, Spain \\ japedros@ucm.es
}

\begin{abstract}
The God who is born from the rock. Comparative aspects of the myth of the birth of Mithras
\end{abstract}

\begin{abstract}
El artículo tiene como objeto mejorar y completar algunas propuestas ya existentes que relacionan el mito del nacimiento del dios romano Mitra de una roca con otras tradiciones como la hitita o algunos mitos de proveniencia minorasiática. Incluyendo datos de la Teogonía hitita, del RigVeda e integrándolos con la información iconográfica del mitraísmo romano y la irania de época sasánida, se propone un origen indoeuropeo para el mito de un dios que nace de una roca.
\end{abstract}

Palabras clave: Mitra Petrogénito; Mihr Yašt; RigVeda; Teogonía hitita; Diorfo; Agdistis; Erictonio; mitraísmo.
This article aims to improve and complete some reconstructive proposals already existing that relate the myth of the Roman God Mithras' birth from a rock with other traditions, namely some Hittite myths or some legends from Minor Asia. By including data from Hittite Theogony and RigVeda and integrating them in a set together with the iconographic information from Roman Mithraism and Sassanid Persia, I propose an Indo-European origin for the myth of the God born from a rock.

Key words: Mithras Petrogenitus; Mihr Yašt; RigVeda; Hittite Theogony; Diorphos; Agdistis; Erichthonius; Mithraism.

Una cuestión ampliamente debatida desde principios del siglo XX es si el mitraísmo romano tiene algún tipo de conexión con el culto a Mithra ${ }^{1}$ iranio, o si, por el contrario, simplemente comparten el nombre de una divinidad y el culto mistérico romano es uno más de los ritos de iniciación que se van popularizando en la antigüedad grecorromana desde el siglo V a. C. El mayor defensor del vínculo entre el culto al Mithra iranio y la religión mistérica de época romana fue Cumont 1900, quien defiende que el mitraísmo de época

${ }^{1}$ Reservamos la transcripción Mithra para las referencias al dios iranio. Para las referencias al dios romano o védico utilizaremos la forma Mitra (cf. Alvar 2008, p. 74).

Copyright: (C) 2016 CSIC. Este es un artículo de acceso abierto distribuido bajo los términos de la licencia de uso y distribución Creative Commons Attribution (CC-by) España 3.0. 
romana es la evolución del mazdeísmo iranio, amalgamado con cosmología caldea y conceptos filosóficos griegos ${ }^{2}$. Ciertamente, la ausencia de cualquier mención a la tauroctonía en nuestra fuente principal para el conocimiento del Mithra iranio, el Yašt $10^{3}$, y la importancia de los elementos astrológicos del culto mitraico romano han sido puestos de manifiesto como objecciones a la teoría de Cumont ${ }^{4}$. Una corriente completamente contraria a relacionar el mitraísmo romano con el culto a Mithra iranio fue inaugurada por Gordon 1975, quien, tras realizar una profunda crítica a las teorías de Cumont, piensa que los misterios mitraicos carecen de relación con el zoroastrismo. Esta crítica fue continuada por Clauss 2000, quien considera que los misterios mitraicos tuvieron su origen en la ciudad de Roma o en el puerto de Ostia. Del mismo modo, Beck 2006 piensa que los misterios mitraicos romanos son una creación completamente occidental. Para estos autores, el eje argumental de la discusión sobre el origen iranio u occidental de los misterios mitraicos se centra en la ausencia de concomitancias entre el Mithra iranio y el Mitra romano tanto en los aspectos iconográficos cuanto en lo que sabemos sobre el ritual.

Uno de los episodios míticos del Mitra romano que está mejor ilustrado por la iconografía ${ }^{5}$ por $\operatorname{los}_{\text {textos }}^{6}$ es el nacimiento de Mitra de una roca. Ulansey

2 Autores como Campbell 1968 o Campos 2006 siguen considerando indispensable ligar la tradición religiosa irania con el origen del mitraísmo romano.

${ }^{3}$ Nuestro conocimiento del Mithra iranio viene dado fundamentalmente por el himno que le es dedicado en el Avesta, dentro de la colección de textos hímnicos de carácter litúrgico que conocemos con el nombre de Yašts. En concreto, Mithra tiene dedicado el himno número 10, conocido con su nombre pahlavi Mihr Yašt, ed. Gershevitch 1959, el himno que se recita el decimosexto día del mes zorastriano de treinta días: Choksy-Kotwal 2005. El himno a Mithra es una acumulación de fórmulas devocionales en las que el adorador enumera, aparentemente de manera inconexa y desordenada, los rasgos principales del dios por los que merece el sacrificio: Kellens 2000, Pirart 2006, p. 23.

${ }^{4}$ Sobre la importancia de la cosmología en el culto mitraico, v. entre otros Ulansey 1989.

${ }^{5}$ Las referencias se pueden encontrar en Vermaseren 1982, pp. 69-73. Un análisis sobre la importancia del Mitra Petrogénito en la iconografía mitraica se puede leer en Neri 2000. La conexión de la representación iconográfica de Mitra Petrogénito con la astrología neoplatónica ha sido estudiada por Alvar 2008, p. 83.

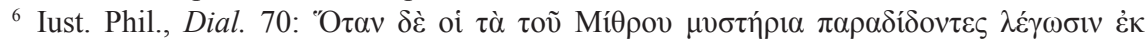

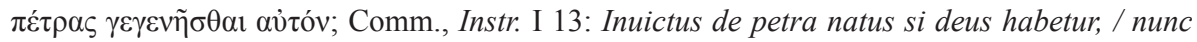
ego reticio; uos de istis date priorem. / Vicit petra deum, quaerendus est petra creator (...)

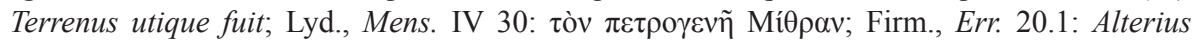

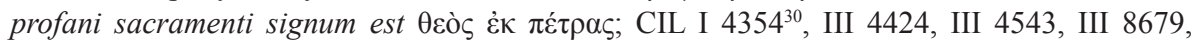
XIII 7369: Petrae genetrici. 
1989 , p. 35 defiende que este nacimiento tiene que ver con la leyenda de Perseo, nacido en una cámara subterránea, y que Mitra fue «forced out of the rock as if by some hidden magic power». Sin embargo, el nacimiento de Mitra de una roca presenta una posible relación con el Yašt 10, que fue puesta de relieve por Vermaseren 1951. En dicho himno el dios aparece resplandeciente en la cima del monte Harā, identificable con la cordillera del Alborz, desde la que contempla todo el país de los arios. La importancia de ese pasaje para entender el origen del mito ha sido puesta de relieve sobre todo por Burkert 1979, quien ha señalado el paralelo del nacimiento de Agdistis, narrado por Arnobio y el nacimiento de Mitra de una roca del relato de Pseudo-Plutarco ${ }^{7}$ con el mito hitita en el que Kumarbi escupe el semen de Anu sobre una roca, de la que nace Ullikummi, un gigante de diorita (CTH 345). El paralelo del texto hitita con otras leyendas similares de Anatolia y el Cáucaso está bien documentado por de Jong 1997, p. 290-299). El autor que explota mejor desde el punto de vista comparativo dichos textos es Mastrocinque 2009, p. 74-81, incluyendo los mitos de fecundación de una roca protagonizados por Mitra y el monte Diorfo, por Júpiter y la roca Agdo y por Hefesto y Atenea para concluir de manera plausible que «la combinación de la tradición órfica y platónica de los sueños y las contemplaciones de Crono con la tradición anatolia de la fecundación de la roca podría haber dado lugar a la tradición del nacimiento en la tierra de un dios inteligible, hipercósmico, que podía solamente ser pensado».

Si bien la fuerza argumental de la línea comparativa permanece intacta tras los trabajos de Burkert, de Jong y Mastrocinque y refuerza la idea de que el mitraísmo romano es una combinación de elementos tradicionales indoeuropeos (no solo iranios), más elementos órficos y neoplatónicos, hay algunos elementos de la comparación que permanecen sin explotar y otros que quizá no estén bien integrados en la comparación. Por ejemplo, en el mito anatolio de Ulikummi, el ser que nace de la roca es un monstruo que poco tiene que ver con el Mitra romano, que es un dios de salvación ${ }^{8}$. La subida al monte Harā de Mithra en el Yašt 10 no constituye en sí misma el nacimiento del

7 Para la historia de Diorfo, v. Ps.-Plu., Fluu. XXIII 4. El mito del nacimiento de Agdistis lo recogen Arnob., Nat. V 5. y Paus. VII 17.9-12, cf. Alvar 2008, pp. 65-67. Lancellotti 2002, p. 2 no las considera dos versiones del mismo mito. Para el mito del nacimiento de Erictonio usaremos Apollod. III 14.6. Sobre estos cuatro textos volveremos más adelante, porque son importantes para nuestra demostración.

${ }^{8}$ Lancellotti 2002, pp. 21-23 señala también las diferencias funcionales entre el nacimiento de Ullikummi y el de Agdistis. 
dios. Cuando es Mitra el dios que engendra en la leyenda transmitida por Pseudo-Plutarco, lo que nace es un héroe que posteriormente fracasa en su combate con Ares. El ser nacido del semen de Júpiter caído sobre la roca Agdo, según la narración de Arnobio, es Agdistis, un ser hermafrodita, furioso y cruel, algo similar a lo que sucede con Erictonio, nacido del semen de Hefesto derramado sobre la tierra, quien tiene rasgos monstruosos, si seguimos el relato de Apolodoro. Todos estos detalles pueden ser comparados para restituir una antigua teogonía indoeuropea, pero a mi modo de ver deben ser perfilados y los datos han de ser mejor integrados.

Aumentaremos los elementos susceptibles de ser comparados, incluyendo datos procedentes de la tradición india, en concreto, el himno RV VII 33, en la que el semen de Mitra-Varuna derramado en un jarro da lugar al nacimiento de Māna, padre del ṛ̣i Vasiș̣̂ha.

Asimismo, perfeccionaremos los datos procedentes de los testimonios hititas: tal como resulta del análisis que hace Bernabé 2009 de la teogonía hitita, combinando tres textos, el Canto de Kumarbi, el Canto de Plata y Ea y la Bestia, cuando Kumarbi devora el falo de Anu', éste predice que engendrará cinco dioses ${ }^{10}$. Parece que de la cabeza de Kumarbi nace KA.ZAL, que Bernabé identifica con Ištar. Además, de manera natural «por el buen lugar» nacen el dios Tesub y el río Aranzah. Como Kumarbi ha escupido el semen de Anu sobre la montaña Kanzura, de esta nace el dios [Suwal]iya, identificable, de acuerdo con la profecía de Anu, con Tasmisu, hermano y visir de Tesub (CTH 344). Finalmente, de la profecía recogida en Ea y la Bestia (CTH 351), se deduce también el nacimiento de Zababa.

Por tanto, los elementos de la comparación que plantearemos se pueden resumir en la siguiente tabla:

${ }^{9}$ En la importancia y difusión que adquiere el mito de Kumarbi en la literatura hitita puede haber tenido una notable importancia la existencia de un mito parecido en la literatura mesopotámica, con el prestigio cultural que le era inherente. Se trata del «Prologo del Torneo del Verano contra el Invierno», de la que se conservan diversos testimonios de comienzos del II milenio a. C. Estos textos contienen una variante cosmogónica según la cual el dios Enlil hundió su pene en la «región montañosa» dejándola preñada del Verano y del Invierno (v. Bottéro-Kramer 2004, pp. 493-494).

${ }^{10}$ Teogonía CTH 344, KUB XXXIII 120+119+KUB XXXVI 31, Recto I 31-33. El número de cinco dioses viene confirmado en el texto Ea y la Bestia CTH 351, KUB XXXVI 32+55, col. III 31. La edición canónica de estos textos se encuentra en Laroche 1969. Una edición más reciente se puede consultar en García Trabazo 2002, pp. 155-175. Curiosamente, el Mithra de la cosmogonía maniquea también engendra cinco hijos, v. Sundermann 1979. 
Tabla I.

\begin{tabular}{|c|c|c|c|c|c|c|c|}
\hline & $\begin{array}{l}\text { Teogonía } \\
\text { hitita }\end{array}$ & RV 7.33 & Yt. 10 & $\begin{array}{l}\text { Ps.-Plu. } \\
\text { Fluu. } \\
\text { XXIII } 4\end{array}$ & $\begin{array}{l}\text { Apollod. } \\
\text { III } 14.6\end{array}$ & $\begin{array}{l}\text { Arnob. } \\
\text { V } 5\end{array}$ & $\begin{array}{l}\text { Iconografía } \\
\text { hallada } \\
\text { en los } \\
\text { mitreos }\end{array}$ \\
\hline $\begin{array}{l}\text { Dios } \\
\text { primigenio- } \\
\text { padre }\end{array}$ & Kumarbi & - & $\begin{array}{l}\text { Ahura } \\
\text { Mazdā }\end{array}$ & - & - & - & Saturno \\
\hline $\begin{array}{l}\text { Dios joven- } \\
\text { padre }\end{array}$ & - & - & - & & Hefesto & Júpiter & - \\
\hline Mitra-padre & & $\begin{array}{l}\text { Mitrā } \\
\text {-Varuṇa }\end{array}$ & Mithra & Mitra & - & - & - \\
\hline $\begin{array}{l}\text { Montaña de la } \\
\text { que (re)nace } \\
\text { el dios }\end{array}$ & Kanzura & (jarro) & Harā & Diorfo & - & Agdo & $\begin{array}{l}\text { Petra } \\
\text { genetrix }\end{array}$ \\
\hline $\begin{array}{l}\text { Inseminación } \\
\text { de la montaña }\end{array}$ & Sí & (Sí) & No & Sí & Sí & Sí & No \\
\hline $\begin{array}{l}\text { Parto de la } \\
\text { montaña }\end{array}$ & Sí & (Sí) & No & Sí & Sí & Sí & Sí \\
\hline $\begin{array}{l}\text { Intermediación } \\
\text { femenina }\end{array}$ & No & Sí (Urvasíi) & No & No & $\begin{array}{l}\text { Sí } \\
\text { (Atenea) }\end{array}$ & $\begin{array}{l}\text { Sí } \\
\text { (Cibeles) }\end{array}$ & $\begin{array}{l}\text { Sí } \\
\text { (Victoria ?) }\end{array}$ \\
\hline $\begin{array}{l}\text { Auxiliares en } \\
\text { el parto }\end{array}$ & Gulses & $\begin{array}{l}\text { sacrificios } \\
\text { de los } \\
\text { adoradores }\end{array}$ & $\begin{array}{l}\text { sacrificios } \\
\text { de los } \\
\text { Aməša } \\
\text { Spənta }\end{array}$ & - & - & - & $\begin{array}{l}\text { Cautes y } \\
\text { Cautopates }\end{array}$ \\
\hline $\begin{array}{l}\text { Nacimiento de } \\
\text { un héroe o un } \\
\text { dios }\end{array}$ & $\begin{array}{l}\text { Cinco dioses: } \\
\text { KA.ZAL, } \\
\text { Tesub, el } \\
\text { río Aranzah, } \\
\text { Suwaliya y } \\
\text { Zababa }\end{array}$ & $\begin{array}{l}\text { Māna, } \\
\text { padre de } \\
\text { Vasiștha }\end{array}$ & $\begin{array}{l}\text { Mithra } \\
\text { renacido }\end{array}$ & Diorfo & Erictonio & Agdistis & Mitra \\
\hline $\begin{array}{l}\text { Rasgos del } \\
\text { nuevo héroe } \\
\text { o dios }\end{array}$ & $\begin{array}{l}\text { positivos y } \\
\text { negativos }\end{array}$ & positivos & positivos & negativos & $\begin{array}{l}\text { negativos } \\
\text { y positivos }\end{array}$ & negativos & positivos \\
\hline
\end{tabular}

De acuerdo con los elementos de la comparación, nos encontramos con dos tipos de dioses progenitores: dioses antiguos, de la segunda generación de dioses, como es el caso del hitita Kumarbi ${ }^{11}$ (CTH 344); del Crono-Saturno que

${ }^{11}$ Para la posición de Kumarbi dentro de la sucesión de dioses y su relación con la Teogonía de Hesíodo, v. Bernabé 2000. 
se puede ver en el mitreo Barberini de Roma (CIMRM 390), o en los mitreos de Bologna (CIMRM 693), Nersae (CIMRM 650-651), Heddernheim (CIMRM 1083), Osterburken (CIMRM 1292), Neuenheim (CIMRM 1283), Dieburg (CIMRM 1247), Virunum (CIMRM 1430), Mauls (CIMRM 1400), o Poetovio (CIMRM 1593-1594) $^{12}$. En dichas representaciones iconográficas, Crono duerme sobre una roca y no es casualidad que Mitra nazca luego de una roca.

El carácter progenitor de Ahura Mazdā es más complejo de deducir del pasaje del Yašt 10 que nos interesa, pero la expresión recogida en el Yt. 10.12 (50) en donde se dice que Ahura Mazdā ha instaurado a Mithra en una residencia upairi harąm bərəzaitìm «más allá del Harā, la brillante montaña», nos permite deducir que Ahura Mazdā actúa como progenitor de Mithra en su renacimiento al otro lado de la montaña donde se sitúa el Más Allá de la geografía mítica avéstica.

El segundo tipo de dios progenitor es un dios joven, de cualquiera de las últimas generaciones de los dioses de acuerdo con las teogonías indoeuropeas. Este sería el caso del Júpiter que asalta a Cibeles según el relato que recoge Arnobio de Sicca, Nat. V 5.2-4 siguiendo a Timoteo: incestis Iuppiter cupiditatibus adpetivit. El problema es que dicha violación queda en grado de tentativa y el semen del dios se derrama sobre la piedra llamada Agdo: voluptatem in lapidem fudit. La piedra queda preñada del semen de Júpiter y pare un ser llamado, a partir de su madre, Agdistis. En cambio, en Pausanias (VII 17.10), Zeus tiene una emisión seminal durante su sueño y su semen cae en el suelo, algo que recuerda vivamente al sueño del Crono-Saturno de los relieves de los mitreos.

Otro dios joven cuyo semen cae accidentalmente en la tierra para dar lugar a un héroe es Hefesto. El relato está recogido en Apolodoro III 14.6. Igual que en el relato de Arnobio, Hefesto fue poseido por un deseo sexual irrefre-

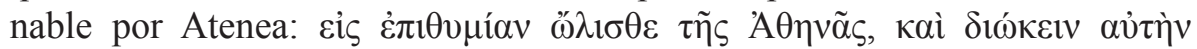
$\eta \eta \eta \xi \alpha \tau$. Ella presentó resistencia hasta que el dios eyaculó en su pierna: ó $\delta \grave{\varepsilon}$

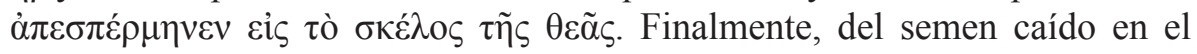
suelo nació el dios Erictonio ${ }^{13}$.

En un tercer grupo de divinidades progenitoras nos encontramos con el propio Mitra. La leyenda conservada por Ps.-Plu. Fluu. XXIII 4 es fácilmente

12 Todos los datos están citados pormenorizadamente en Mastrocinque 2009, p. 74.

13 El paralelo entre Mitra y Erictonio era evidente para los propios antiguos, cf. San Jerónimo Adv. Iouinianum I 7: Mithram et Erichthonium uel in lapide uel in terra solo aestu libidinis esse generatos. 
comparable con las transmitidas por Apolodoro y Arnobio. No es el deseo sexual frustrado el que lleva a Mitra a masturbarse y derramar su semen en una

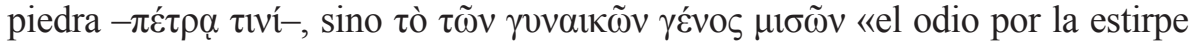
de las mujeres». En cualquier caso, de la piedra fecundada nace Diorfo ${ }^{14}$.

En el RigVeda los dos dioses Mitrā-Varuṇa se masturban como consecuencia del deseo que experimentan por la ninfa Urvaśī, RV VII 33.11: utấsi maitrāvarunó vasișthorváśyā brahman mánasó 'dhi jātáh «y tú, Vasiștha, eres hijo de Mitrā-Varuṇa, nacido del poder mental provocado por Urvaśī» y mezclan su semen en una jarra, de la que nace Māna, que engendra al sabio Vasiștha: RV VII 33.13: satré ha jātấv ișitā námobhih kumbhé rétạh siṣcatuh samānám / táto ha mấna úd iyāya mádhyāt táto jātám ríșim āhur vásiștham «Mediante una gran ofrenda de soma, gracias a las adoraciones, excitados, ambos en común derramaron su simiente en un jarro. De allí surgió Māna, y de él se dice que nació el sabio Vasișțha». La combinación del semen de dos dioses no es algo nuevo en la tradición indoeuropea: se produce también, mediante ingestión, en el mito hitita y en la teogonía de Hesíodo, donde un dios varón traga el falo de otro de un mordisco: la ingesta del falo hace que se combinen el semen de uno y de otro ${ }^{15}$.

En una versión posterior, recogida en el Vāsișthadharmaśāstra XXX 11, el sabio Vasișțha, deseoso de recobrar el cuerpo que había perdido, quiso, por consejo de Brahmā, nacer de la semilla vital de Mitrā-Varuṇa sin el concurso de una mujer. Se amplía el discurso del himno védico, si bien la ninfa Urvaśí aparece como causa del deseo sexual de Varuna. En cualquier caso, el semen de los dioses se deposita en la jarra, de donde nacen Agastya y Vasiștha ${ }^{16}$.

Mitra puede interpretarse como su propio progenitor, en la medida en la que es responsable de su renacimiento como dios protector de los arios cuando sube al monte Harā. Así podríamos interpretar el pasaje del Yašt 10.4 (13) en el que se identifica como el primero de los dioses que sube al monte Harā: yō paoiriiō mainiiauū̄ yazatō / tarō harąm āsnaoiti «el primero de los

${ }^{14}$ Masturbación e ingestión de semen no son elementos exclusivos de la mitología indoeuropea. En el Papiro Chester Beatty 1 encontramos que, en la contienda entre Seth y Horus, tras una humillación sexual del segundo, Isis invierte la situación masturbando a su hijo y colocando su semen en las lechugas del jardín de Seth, para que éste ingiera inadvertidamente su semen. Pero la función del mito es diversa, en cuanto que el semen divino no es generativo, sino que se convierte en la prueba de la victoria de un dios sobre otro.

${ }^{15}$ Cf. Bernabé 1989.

${ }^{16}$ Cf. Gonda 1972, pp. 121-123. 
Yazatas que ha franqueado las cumbres del Harā»». Allí, enriquecido, se convierte en el observador y valedor de todos los arios: adāt visspam àdidāiti / airiiō.șaiianəm səuuištō «allí, enriquecido, tiene ante sus ojos todos los territorios que ocupan los arios». La iconografía nos da una información más clara sobre el renacimiento de Mitra: en un sello sasánida datable en los siglos IV-V d. C. ${ }^{17}$ podemos ver cómo Mitra surge del monte Harā, representado de modo globular, y, en su nueva y gloriosa transformación, se aparece, rodeado por un halo de rayos, a un adorador que le venera con los brazos levantados.

El nacimiento de una montaña es la constante de casi todas estos mitos: entre los hititas es la montaña Kanzura, el monte Diorfo en Pseudo-Plutarco, el monte Agdo en Arnobio, la famosa Petra genetrix en la iconografía del nacimiento del Mitra romano. Mithra es instaurado por Ahura Mazdā en el monte Harā y allí experimenta una suerte de renacimiento. Apolodoro no da ningún nombre especial a la piedra de la que nace Erictonio. Un interesante paralelo textual entre los textos de Arnobio, Pseudo-Plutarco y los textos hititas es remarcar que la montaña cumple los meses de embarazo: Teogonía col I 47, si bien muy fragmentario, formaría parte de la enumeración formular en los textos hititas de la cuenta del embarazo: ITU 7 KAM-aš ti-ya-at

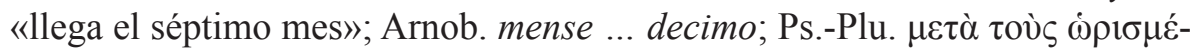

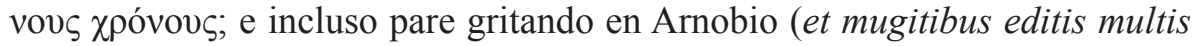
prius). En cambio, en la versión del mito recogida por Pausanias, el semen de Zeus no cae en una roca, sino en la tierra.

La única diferencia esencial la encontramos en el RigVeda, donde el depositario del semen de Mitrā-Varuṇa es un jarro. Sin embargo, también tenemos un paralelo interesante en la iconografía romana: en los mitreos de Salona y $\mathrm{Ostia}^{18}$ aparece en relación directa con Mitra un ánfora, que se interpreta como símbolo de fecundidad, pero que podría tener una relación con el propio nacimiento del dios.

La montaña (o el jarro) quedan preñadas al recibir el semen divino en la mayoría de los mitos, al menos en los más explícitos. El mito avéstico, alta-

${ }_{17}$ Callieri 1990, Grenet 2003.

18 Vermaseren 1951, p. 296. Pero también puede ponerse en relación con la frecuente representación iconográfica de la cratera, relacionada con la recepción de la sangre manante del toro. La relación de Mitra Petrogénico con el crecimiento de las plantas ha sido estudiada por Alvar 2008, p. 84. 
mente elusivo, no contiene ninguna referencia a un acto sexual, sino que parece que la intervención de Ahura Mazdā es esencial para el renacimiento de Mithra. En el nacimiento del Mitra romano a partir de la Petra genetrix no conocemos ningún detalle de actividad sexual. La fecundación de la montaña da lugar, tras su debido tiempo, según especifican Pseudo-Plutarco y Arnobio, a un parto prodigioso, del que nacen los distintos dioses o héroes.

El tema de la intermediación femenina es seguramente el que mayores divergencias suscita en los textos. No se nos cuenta nada en los textos hititas, mientras que en Pseudo-Plutarco se dice explícitamente que el dios Mitra odia la estirpe de las mujeres. Tampoco habla en el texto avéstico de ninguna intervención femenina, si bien el nombre femenino del monte Harā y textos posteriores de autores armenios así lo harían suponer (Vermaseren 1951: 285). Está, sin embargo, muy claro en el texto védico, donde el poder mental (manas-) de Mitrā-Varuṇa se proyecta hacia la ninfa Urvaśi en forma de deseo sexual. En las leyendas recogidas por Apolodoro y Arnobio, el intento de violación de Atenea y Cibeles, respectivamente, es lo que provoca la emisión seminal de Hefesto y Júpiter. En el relieve del mitreo de Poetovio se ve a una diosa o una mujer delante del Saturno dormido sobre la roca, que podría simbolizar también un agente femenino que provoca el deseo sexual del dios (Mastrocinque 2009: 75). Vermaseren (CIMRM 1593) describe dicha figura como «a Victoria flies towards him», lo que pondría en relación la generación de Mitra con su carácter de dios vencedor, esencial dentro de la religión mitraica romana.

El nacimiento de la roca puede ser observado por testigos o por auxiliares especiales que asisten al parto. En el texto hitita comentado por Bernabé (2009: 27), Teogonía col. II.73-84, las Gulses, las divinidades hititas que controlan el destino de los dioses y de los hombres, asisten al parto, cosiendo primero el cráneo de Kumarbi por donde ha salido KA.ZAL (col. II.74: ̌̌e-eku-e-er ta-ar-na-aš-ša-an ${ }^{D} K u$-mar-bi-in) y luego asistiendo (col. II.79: ha$a \check{s}-\check{s} a-n u-e-r a n-a n$ ) al parto «natural» («por el buen lugar» col. II. 84: $a$-a $a s-$ $\check{s} u$-wa-az pí-e-da-az) de Tesub, del Aranzah y de Suwaliya-Tasmisu.

El nacimiento de Mitra Petrogénito es asistido por dos personajes vestidos a la manera persa que pueden ser identificados con Cautes y Cautopates, dado que en algunas casos llevan sus atributos, las antorchas ${ }^{19}$. Aunque la presencia de estos auxiliares se produce solo en nueve monumentos de un total de ciento dieciocho, su paralelo con el mito del parto de la montaña Kanzura los

\footnotetext{
${ }^{19}$ Neri 2000, p. 231.
} 
convierte en un interesante testimonio ${ }^{20}$ de un elemento configurativo del mito del parto de la montaña.

En la tradición indo-irania, mucho más centrada en las implicaciones rituales del mito, el auxilio al nacimiento del dios viene dado por los propios sacrificios, indispensables para cualquier modificación que tenga lugar en el universo en el que se mueven los dioses. Esto queda claro en RV VII 33.13: satré ha jātáv ișitá námobhiḥ «mediante una gran ofrenda de soma, gracias a las adoraciones». En Yt 10.12 (51) es el ritual llevado a cabo por los otros Aməša Spəṇta el que completa el sacrificio de Ahura Mazdā para que Mithra se instaure en el monte Harā: yat karonāun amoș̌ă.spoṇta / vīspe huuaro.hazaoșa / fraorot fraxș̌ni auui manō / zrazdātōit ayuhiiat haca «mientras que los otros Aməša Spəṇta se dedican a cumplir los ritos, de modo unánime y concorde, con aplicación, sabiduría y concentración, con confianza en el rito».

En verdad, donde el mito muestra mayores discrepancias es en el número, nombre y tipo de seres nacidos en este singular parto y posiblemente esto es lo que ha dificultado su interpretación desde un punto de vista comparativo. Ni siquiera su condición divina es equiparable: mientras que en la tradición avéstica nace (o más bien, renace, o se transforma) Mithra, una divinidad ciertamente importante, en el mitraísmo este mismo personaje se convierte en el máximo dios salvador. La tradición griega nos narra mitos en los que intervienen semidioses, como Diorfo o dioses con una importancia más bien local, como Agdistis; por el contrario, Erictonio es el héroe fundador y civilizador de Atenas y termina por ser divinizado. En la tradición védica, del semen derramado por Mitrā-Varuṇa nace Māna, el padre de Vasiṣtha, uno de los ṛ̣is más importantes. El mito hitita es el más complejo pero, a la vez, el que proporciona -a mi modo de ver- las claves para resolver el enigma. El embarazo del monte Kanzura en el mito hitita da nacimiento a cinco dioses: KA.ZAL, que recibe los epítetos UR.SAG-iš LUGAL-uš «héroe, rey», una divinidad soberana que Bernabé 2009, p. 26 identifica con Ishtar a partir, sobre todo, del texto conocido como Canto de Plata (CTH 364); esta divinidad, igual que Atenea, que nació de la cabeza de Zeus, nace por la cabeza de

${ }^{20}$ La presencia de una oveja junto a uno de los personajes (CIMRM 1301, mitreo de Besgheim) ha llevado a interpretar a este auxiliar como un pastor, lo que constituiría un paralelo con la narración del nacimiento de Cristo. Sin embargo, el paralelo con las Gulses hititas dotaría a los auxiliares mitraicos de una mayor antigüedad en el mito. 
Kumarbi. En segundo lugar, «por el buen lugar» nace Tesub, que también recibe el epíteto UR.SAG-iš. A continuación, nace el río Aranzah, y en cuarto lugar Suwaliya, identificado con Tasmisu, hermano y visir de Tesub, que igualmente recibe el epíteto UR.SAG-iš. Finalmente, en el texto Ea y la Bestia (CTH 351) col. III 35-44, se identifica el quinto y último nacimiento del monte Kanzura, Zababa, dios de la guerra. Dos de ellos son grandes dioses de la nueva generación de los dioses hititas. Un tercer dios, Tasmisu-Suwaliya, es una divinidad menor o auxiliar. Completan el elenco las divinidades que no reciben el epíteto UR.SAG-iš: un dios río y el dios de la guerra, que además tiene siempre una nota siniestra.

El carácter anómalo del parto de la montaña provoca que el ser nacido de ella sea, de un modo u otro, también anómalo. No nace un niño, sino un joven, en el mito de Diorfo (véov) y en la iconografía de Mitra Petrogénito. Parece que la misma condición de ser desarrollado está presente en el difícil parto de la montaña Kanzura, que por ello necesita ser suturada por las Gulses. La condición variable de lo parido lleva a que uno de los dioses nacidos del monte Kanzura sea el Aranzah, un río. Erictonio nace con forma de serpiente. El parto de un ser adulto del mito indoeuropeo permite que la tradición avéstica reinterprete con más facilidad el mito como un renacimiento o una glorificación de un dios ya existente.

La multiplicidad de partos del monte Kanzura contenida en el mito hitita nos permite explicar un elemento importante en la comparación de los distintos mitos del dios que nace del monte: su carácter positivo o negativo. De entre los cinco dioses hititas nacidos del Kanzura, tres son descritos como UR.SAG-iš y claramente tienen un carácter positivo: KA.ZAL, Tesub y Tasmisu-Suwaliya. El río Aranzah seguramente es positivo, si bien el carácter fragmentario del texto no nos permite identificar un epíteto. Por su parte, Zababa tiene rasgos más bien negativos y no recibe el epíteto UR.SAG-ǐs. Es decir, el parto múltiple del Kanzura engendra dioses con rasgos también múltiples y esa diversidad está recogida en las otras tradiciones indoeuropeas, seleccionando la variante positiva o negativa, dependiendo del dios que nace de la montaña. Tal como explica Bernabé 2009, p. 29, la unión de la simiente de un dios celeste, Anu, y de un dios ctónico, Kumarbi, es lo que dota a los dioses nuevos que nacen de la combinación de ambas estirpes de un gran poder.

Claramente negativos son los rasgos de Diorfo: lleno de hybris, tiene la osadía de retar a duelo a Ares, lo que lleva a su prematura muerte. Sin embargo, el hecho de que los dioses hayan querido su metamorfosis en una 
montaña -devolviéndole, de alguna manera, a su origen materno- le dota de un final no completamente infeliz y le concede la eternidad.

Con rasgos positivos y negativos se presenta Agdistis. En la versión de Arnobio aparece caracterizado por una fuerza sin control (huic robur invictum et ferocitas animi fuerat intractabilis), y por una líbido desmedida, fruto de su condición bisexual (nsana et furialis libido et ex utroque sexu). La combinación de ambas anomalías le hizo pernicioso para la creación (non deos curare, non homines, nec praeter se quicquam potentius credere terras caelum et sidera continere), lo que llevó a Baco, según la misma narración de Arnobio, a eliminar una de sus dos naturalezas, castrándolo. Sin embargo, en la narración de Paus. VII 17.11 los aspectos del dios distan de ser negati$\operatorname{vos}^{21}$. El carácter bisexual de Agdistis es la combinación de su procredor paterno, un dios masculino y celeste, y de su progenitor materno, la tierra, una diosa ctónica y en la tradición indoeuropea no tiene un carácter negativo, sino generador y positivo ${ }^{22}$.

Algo parecido sucede con Erictonio, quien, si bien nace con rasgos serpentinos que enloquecieron de terror a las hijas de Pandrosio hasta el punto de llevarlas a suicidarse arrojándose de lo alto de la Acrópolis de Atenas, luego se convierte en un héroe fundador y civilizador.

Lo que indiscutiblemente une el mito en su variante indo-irania y la refección que de él hace el mitraísmo romano es la selección de rasgos únicamente positivos en el dios que nace de la roca. Ya hemos vistos que quien nace del semen de Mitrā-Varuṇa depositado en el jarro en la tradición védica es el padre del sabio Vasiștha, uno de los siete grandes ṛ̣is de la tradición védica y uno de los dos mortales (junto a Bhava) al que le está dedicado un himno del RigVeda. Su condición de gran ṛ̣i le convierte en un benefactor para la humanidad, rasgo que comparte con el Mithra avéstico y el Mitra romano.

La subida de Mithra al monte Harā marca claramente su transformación, en virtud de la máxima voluntad de Ahura Mazdā y de los sacrificios de los restante Aməša Spəṇta, y su conversión en el dios que vela desde las alturas por el bienestar de los arios. En cierto modo, la subida al monte Harā es una suerte de renacimiento del dios, propiciada por la condición celeste que tiene

\footnotetext{
${ }^{21}$ Lancellotti 2002, p. 23.

${ }^{22}$ Tal como demuestra Campbell 1968, pp. 155-157 a partir de textos de la tradición religiosa indo-irania.
} 
la montaña en la geografía mítica avéstica. La condición sutil propia de la literatura avéstica, centrada en el aspecto ritual, permite relacionar esta ascensión y transformación del Mithra con el mito del nacimiento de un dios a partir del semen derramado por un dios progenitor sobre una montaña. En la adaptación romana del mito, el nacimiento del Deus saxigenus se integra, con el mito del Taurophoros en el Transitus Dei o paso del dios entre dos mundos, por lo que no es descabellado entender que el nacimiento de Mitra Petrogénito representa en sí mismo, igual que en el pasaje avéstico, una suerte de regeneración física y espiritual ${ }^{23}$.

En conclusión, los materiales comparativos subrayan el carácter indoeuropeo del mito del dios que nace de una montaña y el carácter transformador que tiene dicho nacimiento, plasmado de modo literario y cultual en la subida del Mithra avéstico al monte Harā y su conversión en benefactor máximo de los arios, que está en las raíces la leyenda mitraica del nacimiento de Mitra Petrogénito, quien nace como un joven lleno de fuerza para realizar el sacrificio del toro. Sin duda, dicho mito indoeuropeo es reinterpretado por una tradición filosófica muy posterior para dar lugar a una religión de salvación.

\section{BIBLIOGRAFÍA}

Alvar, J. 2008: Romanising Oriental Gods. Myth, Salvation and Ethics in the Cults of Cybele, Isis and Mithras, Leiden.

Beck, R. 2006: The Religion of the Mithras Cult in the Roman Empire, Oxford.

Bernabé, A. 1989: «Generaciones de dioses y sucesión interrumpida. El mito hitita de Kumarbi, la Teogonía de Hesíodo y el Papiro de Derveni», Aula Orientalis 7, pp. 159-179.

Bernabé, A. 2000: «Los mitos hititas sobre Kumarbi y la Teogonía de Hesíodo: semejanzas en la forma y diversidad de concepción religiosa», Cadmo. Revista do Instituto Oriental Universidade de Lisboa 10, pp. 147-166.

Bernabé, A. 2009: «El extraordinario embarazo de Kumarbi», en Barreira, D. A. y del Olmo, G. (eds.), Reconstructing a Distant Past. Ancient Near Eastern Essays in Tribute to Jorge R. Silva Castillo, Sabadell, pp. 23-30.

Bottéro, J. y Kramer, S. N. 2004: Cuando los dioses hacían de hombres, Mitología mesopotámica, Madrid.

${ }^{23}$ Campbell 1968, p. 273. Como señala Alvar 2008, p. 81 «la roca no es solo el mundo, sino también el universo». 
Burkert, W. 1979: «Von Ullikummi zum Kaukasus: die Felsgeburt des Unholds. Zur Kontinuität einer mündlichen Erzählung», Würzburger Jahrbücher N.F. 5, pp. 253-261.

Callieri, P. 1990: «On the Diffusion of the Mithra Images in Sasanian Iran. New evidence from a Seal in the British Museum», East and West 40, pp. 79-98.

Campbell, L. R. 1968: Mithraic Iconography and Ideology, Leiden.

Campos, I. 2006: El dios Mitra: los orígenes de su culto anterior al mitraísmo romano, Las Palmas de Gran Canaria.

Choksy, J. y Kotwal, F. M. 2005: «Praise and Piety: Niyāyišn and Yašts in the History of Zoroastrian Praxis», BSOAS 68, pp. 215-252.

CIL: Corpus Inscriptionum Latinarum.

CIMRM: Vermaseren, M. J. 1956-1960: Corpus inscriptionum et monumentorum religionis Mithriacae I-II, La Haya.

Clauss, M. 2000: The Roman cult of Mithras: the god and his mysteries, Edimburgo.

CTH: Lejeune, E. 1971: Catalogue des textes Hittites, París, Klincksieck. Actualizado en internet: S. Košak - G. G. W. Müller, hethiter.net/: Catalog (2014-07-28); $<$ http://www.hethport.uni-wuerzburg.de/CTH/>

Cumont, F. 1900: Les mystères de Mithra, Bruselas.

García Trabazo, J. V. 2002: Textos religiosos hititas, Madrid.

Gershevitch, I. 1959: The Avestan Hymn to Mithra. With an introduction, translation and commentary, Cambridge.

Gonda, J. 1972: The Vedic God Mitra, Leiden.

Gordon, R. L. 1975: «Franz Cumont and the Doctrines of Mithraism», en Hinnells, J. R. (ed.), Mithraic Studies I, Manchester, pp. 215-48.

Grenet, F 2003: «Mithra, dieu iranien: nouvelles données», Topoi 11, pp. 35-58.

de Jong, A. 1997: Traditions of the Magi: Zoroastrianism in Greek and Latin literature, Leiden.

Kellens, J. 2000: «Promenade dans les Yašts à la lumière de travaux récents», Annuaire du Collège de France 1998-1999. Résumés des cours et travaux, 99e année, París, pp. 688-690.

Lancellotti, M. G. 2002: Attis, Between Myth and History: King, Priest and God, Leiden.

Laroche, E. 1969: Textes mythologiques hittites en transcription, París.

Mastrocinque, A. 2009: Des Mystères de Mithra aux Mystères de Jésus, Stuttgart.

Neri, I. 2000: «Mithra Petrogénito. Origine iconografica e aspetti cultuali della nascita dalla pietra», Ostraka 9, pp. 227-245.

Pirart, E. 2006: Guerriers d'Iran. Traductions annotées des textes avestiques du culte zoroastrien rendu aux dieux Tištrya, Mïra et Vṛragna, París.

RV: RigVeda. 
Sundermann, W. 1979: "The Five Sons of the Manichaean God Mithra», en Bianchi, U. (ed.), Mysteria Mithrae. Proceedings of the International Seminar on the Religion-Historical Character of Roman Mithraism with Particular Reference to Roman an Ostian Sources, Roma, pp. 485-499.

Ulansey, D. 1989: The Origins of the Mithraic Mysteries: Cosmology and Salvation in the Ancient World, Oxford.

Vermaseren, M. J. 1951: «The miraculous Birth of Mithras» Mnemosyne 4, pp. 285-301.

Vermaseren, M. J. 1982: Mithriaca. III. The Mithraeum at Marino, Leiden.

Yt.: Yašt.

Fecha de recepción de la primera version del artículo: 12/03/2015

Fecha de aceptación: 10/07/2015

Fecha de recepción de la version definitiva: 21/07/2015 